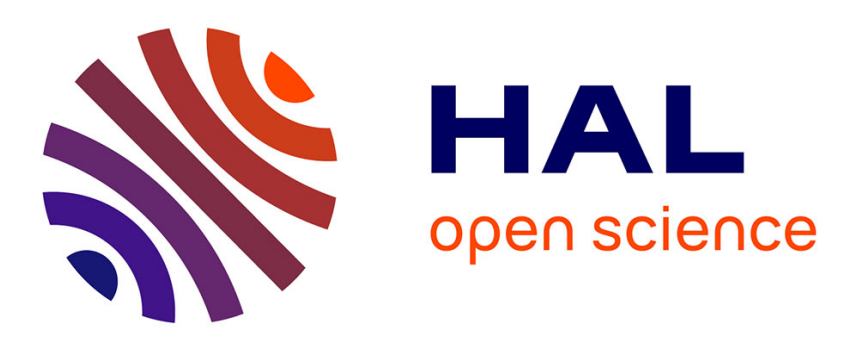

\title{
Silicon isotope measurement in zircon by laser ablation multiple collector inductively coupled plasma mass spectrometry
}

Martin Guitreau, Abdelmouhcine Gannoun, Zhengbin Deng, Johanna Marin-Carbonne, Marc Chaussidon, Frédéric Moynier

\section{To cite this version:}

Martin Guitreau, Abdelmouhcine Gannoun, Zhengbin Deng, Johanna Marin-Carbonne, Marc Chaussidon, et al.. Silicon isotope measurement in zircon by laser ablation multiple collector inductively coupled plasma mass spectrometry. Journal of Analytical Atomic Spectrometry, 2020, 35 (8), pp.15971606. 10.1039/D0JA00214C . hal-02944428

\section{HAL Id: hal-02944428 \\ https://hal.uca.fr/hal-02944428}

Submitted on 23 Sep 2020

HAL is a multi-disciplinary open access archive for the deposit and dissemination of scientific research documents, whether they are published or not. The documents may come from teaching and research institutions in France or abroad, or from public or private research centers.
L'archive ouverte pluridisciplinaire HAL, est destinée au dépôt et à la diffusion de documents scientifiques de niveau recherche, publiés ou non, émanant des établissements d'enseignement et de recherche français ou étrangers, des laboratoires publics ou privés. 


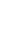

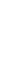
0 1

\section{Silicon isotope measurement in zircon by laser ablation}

$$
\text { multiple collector inductively coupled plasma mass }
$$

\section{spectrometry}

Martin Guitreau $^{1^{*}}$, Abdelmouhcine Gannoun ${ }^{1}$, Zhengbin Deng $^{2 * *}$, Johanna MarinCarbonne $^{3}$, Marc Chaussidon ${ }^{2}$ Frédéric Moynier ${ }^{2}$

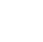

${ }^{1}$ Université Clermont Auvergne, CNRS, IRD, OPGC, Laboratoire Magmas et Volcans, UMR 6524, F63000, Clermont-Ferrand, France.

${ }^{2}$ Université de Paris, Institut de Physique du globe de Paris, CNRS UMR 7154, 75005 Paris, France

${ }^{3}$ Institut des Sciences de la Terre, Université Lausanne, Géopolis Mouline, 1015 Lausanne,

Switzerland

*Correspondence: martin.guitreau@uca.fr

** Present address: Centre for Star and Planet Formation, Globe Institute, University of Copenhagen, Copenhagen, Denmark

\section{ABSTRACT}

3 This study reports the first Si isotope data measured in zircon using nanosecond laser ablation multiple collector inductively coupled plasma mass spectrometry. 5 Long-term (>2 years) external reproducibility obtained on the 91500 zircon standard is $0.13 \%$ and $0.21 \%$ (2SD) for $\delta^{29} \mathrm{Si}$ and $\delta^{30} \mathrm{Si}$ (per mil deviation from the 
quartz reference NBS 28), respectively, and typical precision on a single run is on the order of $0.10 \%$ and $0.12 \%$ (2SE) for $\delta^{29} \mathrm{Si}$ and $\delta^{30} \mathrm{Si}$, respectively. Our results show good consistency between laser ablation multiple collector inductively coupled plasma mass spectrometry (LA-MC-ICP-MS) and solution multiple collector inductively coupled plasma mass spectrometry (S-MC-ICP-MS) / secondary ionization mass spectrometry (SIMS) data demonstrating that the Si isotopic composition of zircon can be accurately measured by LA-MC-ICP-MS. Obtained $\delta^{30}$ Si values on natural zircon standards range from $-0.32 \pm 0.23 \%$ (2SD) for 91500 to $\mathbf{- 0 . 4 7} \pm \mathbf{0 . 1 7 \%}$ for MudTank, whereas the MUN (synthetic) zircon standards have lower $\delta^{30}$ Si values around $-2.0 \%$ (e.g. $-2.08 \pm 0.17 \%$ for MUN-12b). Silicon isotope measurements by LA-MC-ICP-MS open new possibilities for studying zircon formation in various geological contexts.

\section{Introduction}

Silicon is the third most abundant element on Earth (e.g., McDonough, 2003) and it commonly bonds with oxygen to form $\mathrm{SiO}_{4}$ tetrahedrons that represent the building blocks of all silicates. Silicon is therefore deeply involved in a lot of processes within and at the surface of the Earth. Silicon has three stable isotopes; ${ }^{28} \mathrm{Si}(92.23 \%),{ }^{29} \mathrm{Si}$ (4.68\%), and ${ }^{30} \mathrm{Si}(3.09 \%)$, and the measurement of their relative abundances has long been developed for various applications in planetary and Earth sciences, as well as in biological and environmental studies (e.g., Poitrasson, 2017; Ding et al., 2018; Sutton et al., 2018). Most studies have focused on bulk sample measurement (e.g., Clayton et al., 1978; Ziegler et al., 2005; André et al., 2006; Van den Boorn et al., 2010; Savage et al., 2011; Opfergelt et al., 2012; Zambardi et al., 2013; Deng et al., 2019) but analytical development and scientific needs have conducted to the analysis of $\mathrm{Si}$ 
isotopes with in-situ techniques such as secondary ionization mass spectrometry (SIMS) and laser ablation multiple collector inductively coupled plasma mass spectrometry (LA-MC-ICP-MS) (e.g., Robert and Chaussidon, 2006; Shahar and Young, 2007; Chmeleff et al., 2008; Marin-Carbonne et al., 2010). SIMS measurements successfully helped decipher small scale heterogeneities and processes in $\mathrm{SiO}_{2}$-rich materials and some silicates such as quartz and olivine (e.g., Marin-Carbonne, 2014; Kleine et al., 2018; Villeneuve et al., 2019). This in-situ approach is required to study crystals with complex histories such as zircon $\left(\mathrm{ZrSiO}_{4}\right)$ which has recently been investigated by Trail et al. (2018) using SIMS. The major limitation of these SIMS measurements is the analytical precision which is on average $\sim 0.4 \%$ o $(2 \mathrm{SE})$ and, hence, prevents good resolution between a large amount of data given that high-temperature processes induce limited Si isotope fractionation (e.g., Savage et al., 2014). A few studies utilized LA-MC-ICP-MS to measure Si isotope signatures in rocks and minerals (e.g., Shahar and Young, 2007; Chmeleff et al., 2008; Ziegler et al., 2010; Janney et al., 2011; Schuessler and Blackenburg, 2014; Chen et al., 2016; Frick et al., 2016) and consistently showed that analytical precisions can be better than $0.2 \%$ (2SE). Therefore, LA-MC-ICP-MS could be an alternative and very likely useful technique for in-situ studies of Si isotopes in zircon. These studies also underpinned that the type of laser used (i.e., nanosecond or femtosecond) plays a very important role as $\mathrm{SiO}_{2}$-rich matrices (e.g., quartz, chert) do not always couple well with nanosecond laser beams, thereby inducing poor external reproducibility (e.g., Poitrasson and D’abzac, 2017). However, other types of silicate matrices, such as glass, olivine, and zircon, commonly behave very well which such lasers. Given that the vast majority of LA-MC-ICP-MS facilities are equipped with nanosecond lasers (excimer or solid-state), it seemed more 
useful for the scientific community to develop $\mathrm{Si}$ isotope measurements using nanosecond LA-MC-ICP-MS.

Zircon is a mineral extensively used in Earth Sciences because it can provide precise geochronological information using U-Th-Pb isotope systems (e.g., Tilton et al., 1957; Schoene, 2014), as well as source characteristics using Hf and O isotopes (Patchett, 1983; Valley, 2003). In addition, it is ubiquitous in granite (sensus largo), very resistant to weathering and erosion, and most elements diffuse very slowly within its lattice (Lee et al., 1997; Cherniak and Watson, 2003, 2007). Given that granite is the main constituent of continents, zircon in magmatic rocks and detrital sediments has long been used to study the growth of continents, which remains one of the major unresolved issues in Earth Sciences (e.g., Fedo et al., 2003; Iizuka et al., 2005; Guitreau et al., 2012; Roberts and Spencer, 2015). Silicon stable isotopes have been used to discriminate some granite types from others (Savage et al., 2012; André et al., 2019; Deng et al., 2019) and their application to zircon is promising to study the growth of continents, granite petrogenesis, and lithosphere-hydrosphere interactions in deep-time geology (Trail et al., 2018). Theoretical work predicted that Si isotope fractionation should occur between minerals and their parental melt as a function of temperature, melt polymerization, mineral chemistry and Si-O bond lengths (e.g. Méheut et al., 2009; Méheut and Schauble, 2014; Qin et al., 2016). According to Qin et al. (2016), enrichment in ${ }^{30} \mathrm{Si}$ linked to fractionation follows the sequence quartz $>$ albite $>$ anorthite $>$ olivine $\sim$ zircon $>$ enstatite $>$ diopside. Consequently, zircon is expected to be enriched in light isotopes compared to its parental melt. This was recently confirmed by measurements on natural zircons (Trail et al., 2018) as well as by experimental work (Trail et al., 2019). The present contribution explores the capability of nanosecond LA- 
MC-ICP-MS to measure Si isotopes in individual zircons for future applications in Earth Sciences.

\section{Material and Methods}

\subsection{Standard material}

Reference materials in the form of glass and crystallized matrices (i.e., olivine and zircon) were used for the optimization of the analytical conditions and the determination of an appropriate protocol for silicon isotope measurements by LA-MCICP-MS. Glass reference materials used in this study were SRM NIST 612, USGS BHVO-2 and GSC-1G (e.g., Jochum et al., 2005, 2011). The San Carlos olivine reference material (e.g., Jarosewich et al., 1980) was also investigated together with zircon standards 91500 (syenite-derived; Wiedenbeck et al., 1995), MudTank (carbonatite-derived; Black and Gulson, 1978), KIM (kimberlite-derived; Valley, 2003; Trail et al., 2018), AS3 (gabbro-derived; Paces and Miller, 1993), R33 (monzodioritederived; Black et al., 2004), QGNG (Quartz-gabbronorite-derived; Black et al., 2003), Peixe (Alkaline-rich granitoid-derived; Chang et al., 2006), Plešovice (hyperpotassic granulite-derived; Sláma et al., 2008), and the artificial standards MUN from the Memorial University of NewFoundland (Fisher et al., 2011).

\subsection{Measurements}

\subsubsection{Solution MC-ICP-MS characterization of zircon standards}

In order to determine the Si isotope composition of zircons and to check the validity of results obtained using LA-MC-ICP-MS, we have analyzed several well-known zircon reference materials using solution mode technique (S-MC-ICP-MS) modified from that described in Deng et al. (2019). Crushed powders of 91500 and Plešovice zircons (1.5- 

revised after Georg et al. (2006). The samples were fused in Ag crucibles with proper additions of $\mathrm{NaOH}$ pellet (120 mg for 91500 and Plešovice zircons and only $40 \mathrm{mg}$ for MUN-1) at $720{ }^{\circ} \mathrm{C}$ for $15 \mathrm{~min}$ in a furnace. Afterwards, the glassy samples were dissolved in Milli-Q $\mathrm{H}_{2} \mathrm{O}$ by heating and ultrasonicating. The samples were, then, transferred into pre-cleaned tubes by Milli-Q $\mathrm{H}_{2} \mathrm{O}$ rinsing, achieving total volumes of the solutions for 91500 and Plešovice zircons to $30-40 \mathrm{ml}$ and $10 \mathrm{ml}$ for MUN-1 zircon. This step control in dissolution volume maintains Si concentrations in the sample solutions to be sufficiently high (at $\mu \mathrm{g} / \mathrm{g}$ or sub $\mu \mathrm{g} / \mathrm{g}$ level) for subsequent isotopic measurements. For the digestions on $\geq 1 \mathrm{mg}$ samples, purified $16 \mathrm{M} \mathrm{HNO}_{3}(0.1-0.3$ $\mathrm{mL}$ ) were properly added to acidify the solutions until they became clear. 1.8 mL BioRad AG50X-12 (200-400 meshes) cation exchange resin (Pringle et al., 2014). At neutral conditions, the dissolved $\mathrm{Si}$ would be eluted by $5 \mathrm{~mL}$ Milli-Q $\mathrm{H}_{2} \mathrm{O}$ rinsing, whereas the cations would be retained on the columns by the resin. Note that the resin was discarded after every single use to avoid any memory effect of any neoformed insoluble $\mathrm{Zr}$ particles under weak-acids. After purification, the solutions were further diluted and acidified into $10 \mathrm{~mL}(2 \mu \mathrm{g} / \mathrm{g}) \mathrm{Si}$ solutions in $0.2 \mathrm{M} \mathrm{HNO}_{3}$. The sample solutions were measured for the $\mathrm{Si}$ isotopic compositions on the Thermo

144 Scientific Neptune Plus multi-collector inductively coupled plasma mass spectrometer 145 (MC-ICP-MS) at the Institut de Physique du Globe de Paris (IPGP). The solutions were 146 introduced via a quartz-made spray chamber. The typical sensitivity was $10-12 \mathrm{~V}$ on $147{ }^{28} \mathrm{Si}^{+}$for $2 \mu \mathrm{g} / \mathrm{g}$ of $\mathrm{Si}$ with an uptake rate of $100 \mu \mathrm{L} /$ min under a medium resolution 148 mode $(\mathrm{M} / \Delta \mathrm{M} \sim 5000)$. In order to avoid isobaric interferences from ${ }^{14} \mathrm{~N}^{16} \mathrm{O}^{+}$on ${ }^{30} \mathrm{Si}^{+}$, 149 the measurements of ion intensities were conducted at the lower masses of peaks 28, 

29 and 30 (e.g., Shahar and Young, 2007; Chmeleff et al., 2008; Zhang et al., 2015). Reference materials NBS 28 and BHVO-2 were processed following the same protocols as for zircon standards, and the purified NBS 28 was used as the bracketing standard. A standard-sample bracketing method was used, meaning that NBS 28 solutions were measured before and after each analysis of BHVO-2 and zircon reference material. Each sample was analyzed 3-6 times, and each measurement consisted of 25 cycles with $8.389 \mathrm{~s}$ of integration time per cycle. After every analysis, a wash-out with $0.5 \mathrm{M} \mathrm{HNO}_{3}$ and $0.2 \mathrm{M} \mathrm{HNO}_{3}$ in steps was carried out. The Si blank from the whole procedure was $\leq 15 \mathrm{ng}$, which is much lower than the Si masses of the samples (40-2000 $\mu \mathrm{g})$. After Si purification, each solution was checked using Q-ICPMS and no Zr was detected whereas other elements, when detected, were all below 1 ppb. Note that we managed to strictly match the $\mathrm{NO}_{3}{ }^{-}$contents and $\mathrm{Si}$ concentrations of the bracketing NBS 28 solutions to the corresponding sample solutions, which minimizes possible matrix effects.

\subsubsection{Silicon isotope measurements by LA-MC-ICP-MS}

Laser ablation multiple collector inductively coupled plasma mass spectrometry measurements were conducted at Laboratoire Magmas et Volcans (LMV, ClermontFerrand, France) using a Resonetics Resolution M-50 coupled to a Thermo Scientific Neptune Plus. Analytical conditions are provided in Table 1. The abundance of silicon isotopes was measured in high resolution mode $(\mathrm{M} / \Delta \mathrm{M}=7800)$ and on the low-mass shoulder of 28, 29, and 30 peaks to avoid isobaric interferences (e.g., Shahar and Young, 2007; Chmeleff et al., 2008; Janney et al., 2011; Schuessler and Von Blackenburg, 2014; Frick et al., 2016). Silicon isotope analyses were performed in standard-bracketing (i.e., single measurement of an unknown bracketed by two 
analyses of a matrix-matched standard, or batch of two unknowns bracketed by two measurements of a matrix-matched standard). During the development of the technique, we analyzed quartz, notably NBS 28, and silica-rich matrices (e.g., chert, opale), but observed either very noisy signals or even breakage of crystals during ablation. As a consequence, we could not analyze the international quartz reference standard NBS 28 (NIST RM 8546) to normalize our data to. Instead, we used NIST 612 or the zircon standard 91500 as our normalizing reference and recalculated all data relative to NBS 28. Results are reported in delta notation, $\delta^{29} \mathrm{Si}$ and $\delta^{30} \mathrm{Si}$, which express per mil deviations from a reference, and are calculated using the following equations.

$\delta^{\mathrm{x}} \operatorname{Si}(\% 0)=\left(\frac{\left(\frac{\mathrm{x}_{S i}}{{ }^{28} \mathrm{Si}}\right)_{\text {sample }}}{\left(\frac{\mathrm{x}_{S i}}{28 \mathrm{Si}}\right)_{\text {reference }}}-1\right) \times 1000$

with $\mathrm{x}$ being either 29 or 30 . Several ways of reporting analytical uncertainties have been adopted in the literature (e.g., 1 SD, 1 SE, 2 SD, 2 SE, 95\% confidence). For the sake of consistency, we report internal precision (i.e., within-run error or analytical precision) as 2 standard-errors (2SE), also called reduced-error, which is 2 times the standard-deviation divided by the square-root of the number of measurements. This is the case for single zircon measurement. Note that the internal precision reported for $\delta^{29} \mathrm{Si}$ and $\delta^{30} \mathrm{Si}$ of single measurements include a quadratic addition of the errors on the bracketing standards. The external reproducibility (e.g., mean of measurements on the same zircon standard) is, however, reported as 2 standard-deviations (2SD). When we quote literature data and their associated uncertainties, we report them in the same way as our data and, hence, recalculated them if they were reported differently in the original publications. We processed Si isotope data both with and without applying background correction and observed no difference in the obtained $\delta^{29} \mathrm{Si}$ and $\delta^{30} \mathrm{Si}$. However, data that were corrected for background exhibited poorer external reproducibility likely due 
to the limited signal-over-noise ratio (Fig. 1). As a consequence, all data presented in this contribution were not corrected for background. We also applied a 2SD filter to remove outliers.

A critical issue with high-temperature Si isotope geochemistry is the limited fractionation which, in turn, results in small isotopic variability (e.g., Savage et al. 2014, Deng et al., 2019). This requires an appropriate analytical precision so as to be able to discriminate distinct isotopic compositions. Consequently, we compared $\mathrm{Si}$ isotopes measurements obtained by spot and line modes on synthetic glass, olivine, and zircon standards. We adjusted spot size and frequency together in order to obtain highest and most stable signals, and set the fluence to $\sim 3 \mathrm{~J} / \mathrm{cm}^{2}$ regardless of spot size and frequency used because it corresponds to ablation conditions that are optimal for other isotope systems (i.e., U-Pb and Lu-Hf; Guitreau et al., 2019).

\section{Results}

\subsection{S-MC-ICP-MS results}

Results for basalt (BHVO-2) standards are in good agreement with literature values as we obtained $\delta^{29} \mathrm{Si}$ and $\delta^{30} \mathrm{Si}$ of $-0.14 \pm 0.09$ and $-0.28 \pm 0.15 \%$ o $(\mathrm{n}=60 ; 2 \mathrm{SD})$, respectively which compares well with a $\delta^{30} \mathrm{Si}=-0.29 \pm 0.05 \%$; from Schuessler and Von Blackenburg (2014) (Table 2).

The two different fragments of 91500 analyzed by S-MC-ICP-MS, labeled 91500-MG and 91500-Corfu, exhibit very consistent $\delta^{30}$ Si values of $-0.39 \pm 0.10$ and $0.36 \pm 0.02 \%$ ( $2 \mathrm{SD}$; Table 2). This is also true for $\delta^{29} \mathrm{Si}$ with values of $-0.19 \pm 0.09$ and $-0.20 \pm 0.02 \%$ o (2SD; Table 2). The 4 different fragments of Plešovice zircon standard similarly gave consistent $\delta^{30} \mathrm{Si}$ values between $-0.39 \pm 0.10$ and $-0.34 \pm 0.24 \%$ (2SD; Table 2). The artificial zircon standard MUN-1, which corresponds to MUN-1-2b from 
MUNzirc second series (Hanchar personal communication), gave a mean $\delta^{30} \mathrm{Si}$ value of $-2.08 \pm 0.17 \%$ o (2SD; Table 2 ), which is very light compared to natural zircons. The standards 91500 and Plešovice exhibit similar Si isotope values with those obtained by S-MC-ICP-MS and SIMS in Trail et al. (2018).

\subsection{LA-MC-ICP-MS results}

The results are given in Tables 3-5 and S1-S5, and illustrated in Figures 1-5. Figure 1 shows typical LA-MC-ICP-MS measurements of 91500 in spot and line modes and it is visible that $\mathrm{Si}$ isotopic ratios are stable throughout a run for both modes. The spot measurement (Fig. 1A) is affected by intensity decrease over the course of the analysis which is due to deepening of the laser pit. On the contrary, line mode produces more stable intensities that also translate into more reproducible signals and isotopic ratios. Note that Si backgrounds are high which is common with laser ablation measurements. Table 3 and Figure 2 further show that line mode provides better internal precision and external reproducibility than spot mode regardless of the type of matrix analyzed and laser setting used. Such observation is consistent with those reported by Schuessler and von Blanckenburg (2014). In order to test LA-MC-ICP-MS measurement accuracy, we analyzed San Carlos olivine and 91500 zircon and used NIST 612 as a normalizing reference. It can be seen in Table 4 that obtained $\delta^{29} \mathrm{Si}$ and $\delta^{30} \mathrm{Si}$ for San Carlos and 91500 are inconsistent with expected values. Schuessler and Von Blackenburg (2014) showed that differences in Si intensity between a sample and its bracketing standard could result in inaccurate $\delta^{29} \mathrm{Si}$ and $\delta^{30} \mathrm{Si}$. The synthetic glass, NIST 612 , has a much higher Si concentration than olivine and zircon and, hence, we have adjusted the Si intensity between San Carlos olivine and NIST 612 by changing the frequency of the laser and by doing measurements in line mode. However, obtained values for San 
Carlos olivine are still inaccurate (Table 4) which highlights the matrix-sensitive nature of isotope measurements by LA-MC-ICP-MS using nanosecond lasers. Therefore, all zircon analyses presented in what follows correspond to line mode (Fig. 1B) that were conducted with a frequency of $6 \mathrm{~Hz}$, a spot size of $33 \mu \mathrm{m}$, a fluence of $3 \mathrm{~J} / \mathrm{cm}^{2}$, a traverse rate of $1.6 \mu \mathrm{m} / \mathrm{s}$, and normalized to 91500 . The spot size and frequency were selected to obtain the highest and most stable signal according to the MC-ICP-MS sensitivity without compromising spatial resolution too much.. Data for 91500 gathered over a period of more than 2 years show an external reproducibility of $0.21 \%$ on the selfbracketed $\delta^{30} \mathrm{Si}$ (2SD; Fig. 3), while internal precisions vary between 0.09 and $0.16 \%$ (2SE; Table S3).

Figure $4 \mathrm{a}$ illustrates that LA-MC-ICP-MS data align along a least-squares regression line of $0.5132 \pm 0.0034\left(\mathrm{R}^{2}=0.98\right)$ which falls right in between theoretical predictions for mass-dependent fractionation (i.e., equilibrium $=0.5178$ and kinetic $=$ 0.5092; e.g. Zambardi and Poitrasson, 2011; Savage et al., 2014). Moreover, both SMC-ICP-MS and LA-MC-ICP-MS measurements have consistent fractionation behavior along the terrestrial mass-dependent fractionation lines (Figure 4b). Finally, Figure 5 demonstrates that our new LA-MC-ICP-MS data comply well with Si isotope data obtained with other techniques on the same zircon standards (i.e., S-MC-ICP-MS in this study and S-MC-ICP-MS/SIMS techniques in Trail et al., 2018).

Silicon isotope data for natural zircon standards overall show very little variability with $\delta^{30} \mathrm{Si}$ ranging from $-0.32 \pm 0.23 \%$ for 91500 to $-0.47 \pm 0.17 \%$ or MudTank (2SD; Table 5). These values are consistent with Si isotope data on zircon published elsewhere (Trail et al., 2018, 2019, Figure 5 and Table 5). 91500 zircon analyzed in this study by LA-MC-ICP-MS and by S-MC-ICP-MS gave consistent $\delta^{30} \mathrm{Si}$ of $-0.32 \pm 0.23 \%$ and $-0.39 \pm 0.10 \%$, respectively. AS3 zircon analyzed in this study 
by LA-MC-ICP-MS gave a $\delta^{30} \mathrm{Si}$ of $-0.44 \pm 0.23 \%$ which is consistent within uncertainty-with the value of $-0.36 \pm 0.35 \%$ ( $2 \mathrm{SD}$; Table 5 ) obtained by SIMS in Trail et al. (2018). KIM zircon gave a LA-MC-ICP-MS $\delta^{30} \mathrm{Si}$ of $-0.40 \pm 0.23 \%$ identical to the S-MC-ICP-MS value of $-0.41 \pm 0.01 \%$ from Trail et al. (2018). Kuehl Lake zircon gave a LA-MC-ICP-MS $\delta^{30} \mathrm{Si}$ of $-0.38 \pm 0.12 \%$ which is also consistent within uncertainty with the S-MC-ICP-MS value of $-0.29 \pm 0.04 \%$ published in Trail et al. (2018). MudTank zircon displays a LA-MC-ICP-MS $\delta^{30} \mathrm{Si}$ of $-0.47 \pm 0.17 \%$ which is consistent, within error, with the S-MC-ICP-MS value of $-0.34 \pm 0.03 \%$ from Trail et al. (2018). Plešovice zircon gave a LA-MC-ICP-MS $\delta^{30} \mathrm{Si}$ of $-0.38 \pm 0.18 \%$ identical to S-MC-ICP-MS analyses from this study $\left(\delta^{30} \mathrm{Si}=-0.39 \pm 0.06 \%\right)$. The artificial MUN zircon standards exhibit consistently lighter $\mathrm{Si}$ isotope compositions compared to those shown by natural standards. MUN zircons have slightly variable $\delta^{30} \mathrm{Si}$ that range from $-1.67 \pm 0.14 \%$ o for MUN-0 to $-2.05 \pm 0.30 \%$ ( $2 \mathrm{SD}$; Table 5 ) for MUN-4. The value of $-2.00 \pm 0.22 \%$ obtained for MUN-1 using LA-MC-ICP-MS (Table 5) is identical within uncertainty to that obtained by S-MC-ICP-MS (i.e., $-2.08 \pm 0.17 \%$; Table 2), hence, confirming the enrichment of this synthetic zircon in light Si isotopes.

\section{Discussion}

Comparisons between Si isotope signatures of natural and synthetic zircons analyzed by LA-MC-ICP-MS and S-MC-ICP-MS in this study, as well as data from the literature (S-MC-ICP-MS and SIMS, Trail et al., 2018), exhibit general good consistency that indicates that zircon data by LA-MC-ICP-MS are accurate and robust. Moreover, although less precise than S-MC-ICP-MS analyses $\left(\delta^{30} \mathrm{Si}\right.$ within-run 2 standard error of $\sim 0.02-0.05 \%$ ), LA-MC-ICP-MS data $\left(\delta^{30} \mathrm{Si}\right.$ within-run 2 standard error of $\sim 0.10$ $0.15 \%)$ are more precise than currently available SIMS data $\left(\delta^{30} \mathrm{Si}\right.$ within-run 2 

studied.

standard error of $\sim 0.30-0.40 \%$ ) and, hence, represent a relevant compromise between precision and spatial resolution. Therefore, Si isotope measurements in zircon by LAMC-ICP-MS open new possibilities for zircon studies in various geological contexts (e.g., magmatic differentiation, crustal growth).

This technique could be improved further in the future by reducing the high $\mathrm{Si}$ background which is visible in Figure 1 and likely influences external reproducibility of Si isotope signatures. Moreover, as shown in Zambardi and Poitrasson (2011) silicon isotopic fractionation induced by MC-ICP-MS instruments evolve non-linearly over time, which requires a strict standard-bracketing procedure to be applied when measuring Si isotopes by LA-MC-ICP-MS. However, if ways to stabilize the timeinduced drift in Si isotope ratios in MC-ICP-MS are found they would certainly help improve external reproducibility of $\delta^{29} \mathrm{Si}$ and $\delta^{30} \mathrm{Si}$.

One pitfall of LA-MC-ICP-MS analysis, compared to SIMS, is the quantity of material required to achieve reasonable precision. In this contribution, we have decided to conduct analyses in line mode so as to obtain the best internal precision and external reproducibility. In the context of zircon studies, processing by lines over spots has the advantage of better coupling internal textures observed in cathodoluminescence (CL) and back-scattered electron (BSE) images to the obtained isotopic information. However, such lines require a rather large part of zircons to be swept across $(\sim 100 \mu \mathrm{m}$ long traverse). Possible chemical/isotopic heterogeneities may be invisible at the sampling scale. One may compromise the precision for spatial resolution by doing spots but would likely reduce the precision and hence the resolvability. This issue can be dealt with on a case-to-case basis depending on the size and complexity of zircons 


\section{Conclusions}

In this contribution, we have set up a protocol for Si isotope measurements in zircon by nanosecond LA-MC-ICP-MS. Analyses performed in line mode were preferred to those obtained by spot mode because of their better internal precision and external reproducibility. Within-run error on zircon $\delta^{30} \mathrm{Si}$ are on the order of $\sim 0.10-0.15 \%$ o (2SE) and external precision of $\sim 0.15-0.30 \%$ (2SD). Our LA-MC-ICP-MS data are in line with those acquired with S-MC-ICP-MS and SIMS, therefore highlighting the accuracy of silicon isotope measurements in zircon by LA-MC-ICP-MS. This technique, therefore, offers an additional way to existing methods aiming to study zircon formation in different geological contexts.

\section{Conflicts of interest}

The authors have no conflicts to declare.

\section{Acknowledgements}

Dustin Trail is thanked for providing KIM and KL zircons as well as for stimulating discussions. Fernando Corfu is thanked for providing a 91500 zircon fragment. M.G. acknowledges financial support from the Région Auvergne through the Auvergne Fellowship program, LabEx ClerVolc (ANR-10-LABX-0006) and the French Agence Nationale de la Recherche through funded ANR-JC project Zircontinents (ANR-17CE31-0021). This is a Laboratory of Excellence ClerVolc contribution number 418. F.M. acknowledges funding from the European Research Council under the H2020 framework program/ERC grant agreement \#637503 (Pristine). F.M. and M.C. thank the financial support of the UnivEarthS Labex programme at Université de Paris (ANR10-LABX-0023 and ANR-11-IDEX-0005-02). Finally, we are grateful to Harriet 
Brewerton for efficient editorial handling and to two anonymous reviewers who helped

350 clarify the manuscript and data presentation.

\section{References}

1. McDonough, W.F. Compositional model for the Earth's core. In: Holland, H.D., $547-568$.

2. Poitrasson F. Silicon isotope geochemistry. Reviews in Mineralogy and Geochemistry. 2017; 82: 289-344.

3. Ding T., Jiang S., Li Y., Gao J., Hu B. Geochemistry of silicon isotopes. De Gruyter.

4. Sutton J.N., André L., Cardinal D., Conley D.J., de Souza G.F., Dean J., Dodd J., Ehlert C., Ellwood M.J., Frings P.J., Grasse P., Hendry K., Leng M.J., Michalopoulos P., Panizzo V.N., Swann G.E.A. A Review of the Stable Isotope Bio-geochemistry of the Global Silicon Cycle and Its Associated Trace Elements. Frontiers in Earth Sciences. 2018; 5(112): 1-24.

5. Clayton R.N., Mayeda T.K., Epstein S. Isotopic fractionation of silicon in Allende inclusions. Proceedings of the $9^{\text {th }}$ Lunar and Planetary Science Conference. 1978: $1267-1278$.

6. Ziegler K., Chadwick O.A.,White A.F., Brzezinski M.A. $\delta 30$ Si systematics in a granitic saprolite, Puerto Rico. Geology. 2005; 33: 817-820.

7. André L., Cardinal D., Alleman L.Y., Moorbath S. Silicon isotopes in $~ 3.8$ Ga West Greenland rocks as clues to the Eoarchean supracrustal Si cycle. Earth and Planetary Science Letters. 2006; 245: 162-173. 
8. Van den Boorn S.H.J.M., van Berger M.J., Vroon P.Z., de Vries S.T., Nijman W. Silicon isotope and trace element constraints on the origin of $\sim 3.5 \mathrm{Ga}$ cherts: Implications for early Archaean marine environments. Geochimica et Cosmochimica Acta. 2010; 74: 1077-1103.

9. Savage P.S., Georg R.B., Williams H.M., Burton K.W., Halliday A.N. Silicon isotope fractionation during magmatic differentiation. Geochimica et Cosmochimica Acta. 2011; 75: 6124-6139.

10. Opfergelt S., Georg R.B., Delvaux B., Cabidoche Y.-M., Burton K.W., Halliday A.N. Silicon isotopes and the tracing of desilication in volcanic soil weathering sequences, Guadeloupe. Chemical Geology. 2012; 326: 113-122.

11. Zambardi T., Poitrasson F., Corgne A., Méheut M., Quitté G., Anand M. Silicon isotope variations in the inner solar system: implications for planetary formation, differentiation and composition. Geochimica et Cosmochimica Acta. 2013; 121: 67-83.

12. Deng Z., Chaussidon M., Guitreau M., Puchtel I., Dauphas N., Moynier F. An oceanic subduction origin for Archaean granitoids revealed by silicon isotopes. Nature Geoscience. 2019; 12: 774-778

13. Robert F., Chaussidon M. A. Palaeotemperature curve for the Precambrian oceans based on silicon isotopes in cherts. Nature. 2006; 443: 969-972.

14. Shahar A., Young E.D. Astrophysics of CAI formation as revealed by silicon isotope LA-MC-ICPMS of an igneous CAI. Earth and Planetary Science Letters 2007; 257: 497-510.

15. Chmeleff J., Horn I., Steinhoefel G., von Blanckenburg F. In situ determination of precise stable Si isotope ratios by UV-femtosecond laser ablation high-resolution multi-collector ICP-MS. Chemical Geology. 2008; 249: 155-166. 
16. Marin-Carbonne J., Chaussidon M., Robert F. Microscale oxygen isotope variations in $1.9 \mathrm{Ga}$ Gunflint cherts: assessments of diagenesis effects and implications for oceanic paleo-temperature reconstructions. Geochimica et Cosmochimica Acta. 2010; 74: 116-130.

17. Marin-Carbonne J., Robert F., Chaussidon M. The silicon and oxygen isotope compositions of Precambrian cherts: A record of oceanic paleo-temperatures. Precambrian Research 2014; 247: 223-234.

18. Kleine B.I., Stefánsson A., Halldórsson S.A., Whitehouse M.J., Jónasson K. Silicon and oxygen isotopes unravel quartz formation processes in the Icelandic crust. Geochemical Perspectives Letters. 2018; 7: 5-11.

19. Villeneuve J., Chaussidon M., Marrochi Y., Deng Z., Watson E.B. High-precision in situ silicon isotopic analyses by multi-collector secondary ion mass spectrometry in olivine and low-calcium pyroxene. Rapid Communications in Mass Spectrometry. 2019; 33: 1589-1597.

20. Trail D., Boehnke P., Savage P. S., Liu M. C., Miller M. L., Bindeman I. Origin and significance of $\mathrm{Si}$ and $\mathrm{O}$ isotope heterogeneities in Phanerozoic, Archean, and Hadean zircon. Proceedings of the National Academy of Science (USA). 2018; 115: 10287-10292.

21. Savage P.S., Armytage R.M.G., Georg R.B., Halliday A.N. High temperature silicon isotope geochemistry. Lithos. 2014; 190-191: 500-519.

22. Ziegler K., Young E.D., Schauble E.A., Wasson J.T. Metal-silicate silicon isotope fractionation in enstatite meteorites and constraints on Earth's core formation. Earth and Planetary Science Letters. 2010; 295: 487-496.

23. Janney P.E., Richter F.M., Mendybaev R.A., Wadhwa M., Georg R.B., Watson E.B., Hines R.R. Matrix effects in the analysis of $\mathrm{Mg}$ and $\mathrm{Si}$ isotope ratios in 
natural and synthetic glasses by laser ablation-multicollector ICPMS: A comparison of single- and double-focusing mass spectrometers. Chemical Geology. 2011; 281:26-40.

24. Schuessler J.A., von Blackenburg F. Testing the limits of micro-scale analyses of Si stable isotopes by femtosecond laser ablation multicollector inductively couple plasmla mass spectrometry with application to rock weathering. Spectrochimica Acta Part B. 2014; 98: 1-18.

25. Chen X., Chafetz H.S., Andreasen R., Lapen T. Silicon isotope compositions of euhedral authigenic quartz crystals: implications for abiotic fractionation at surface temperatures. Chemical Geology. 2016; 423: 61-73.

26. Frick D.A., Schuessler J.A., von Blanckenburg F. Development of routines for

27. Poitrasson F., D’Abzac F.-X. Femtosecond laser ablation inductively coupled plasma source mass spectrometry for elemental and isotopic analysis: are ultrafast lasers worthwile? Journal of Analytical Atomic Spectrometry. 2017;

28. Tilton G.R., Davis G.L., Wetherill, G.W., Aldrich L.T. Isotopic ages of zircon from granites and pegmatites. Transactions American Geophysical Union. 1957;

444 29. Schoene $\mathrm{S} . \mathrm{U}-\mathrm{Th}-\mathrm{Pb}$ geochronology. In: Treatise on Geochemistry, $2^{\text {nd }}$ edition, Elsevier, Oxford. 2014; $4.10: 341-378$. 
30. Patchett P.J. Importance of the Lu-Hf isotopic system in studies of planetary chronology and chemical evolution. Geochimica et Cosmochimica Acta 1983; 47: 81-91.

31. Valley J. Oxygen isotopes in zircon. Reviews in Mineralogy and Geochemistry. 2003; 53: 343-385.

32. Lee J.K.W., Williams I.S., Ellis D.J. Pb, U and Th diffusion in natural zircon. Nature. 1997; 390:159-162.

33. Cherniak D. J., Watson, E. B. Diffusion in zircon. Reviews in Mineralogy and Geochemistry, 2003; 53: 113-143.

34. Cherniak D.J., Watson, E.B. Ti diffusion in zircon. Chemical Geology. 2007; 242: 470-473.

35. Fedo C.M., Sircombe K.N., Rainbird R.H. Detrital zircon analysis of the sedimentary record. Reviews in Mineralogy and Geochemistry, 2003; 53: 277303.

36. Iizuka T., Hirata T., Komiya T., Rino S., Katayama I., Motoki A., Maruyama, S. $\mathrm{U}-\mathrm{Pb}$ and $\mathrm{Lu}-\mathrm{Hf}$ isotope systematics of zircons from the Mississippi river sand: implications for reworking and growth of continental crust. Geology. 2005; 33 : $485-488$.

37. Guitreau M., Blichert-Toft J., Martin H., Mojzsis S.J., Albarède F. Hafnium isotope evidence from Archean granitic rocks for deep-mantle origin of continental crust. Earth and Planetary Science Letters. 2012; 337: 211-223.

38. Roberts N.W., Spencer C.J. The zircon archive of continent formation through time. Geological Society Special Publication. 2015; 389: 197-225. 
39. Savage P.S., Georg R.B., Williams H.M., Turner S., Halliday A.N., Chappell B.W. The silicon isotope composition of granites. Geochimica et Cosmochimica Acta. 2012; 92: 184-202.

40. André L., Abraham K., Hofmann A., Monin L., Kleinhanns, Foley S. Early continental crust generated by reworking of basalts variably silicified by seawater. Nature Geoscience. 2019; 12:769-773.

41. Méheut M., Lazzeri M., Balan E., Mauri F. Structural control over equilibrium silicon and oxygen isotopic fractionation: A first-principles density-functional theory study. Chemical Geology. 2009; 258: 28-37.

42. Méheut M., Schauble E.A. Silicon isotope fractionation in silicate minerals: Insights from first-principles models of phylosilicates, albite and pyrope. Geochimica et Cosmochimica Acta. 2014, 134: 137-154.

43. Qin T., Wu F., Wu Z., Huang F. First-principles calculations of equilibrium fractionation of $\mathrm{O}$ and $\mathrm{Si}$ isotopes in quartz, albite, anorthite, and zircon. Contributions to Mineralogy and Petrology. 2016; 171: 91-104.

44. Trail D., Savage P.S., Moynier F. Experimentally determined Si isotope fractionation between zircon and quartz. Geochimica et Cosmochimlica Acta. 2019; 260: 257-274.

45. Jochum K.P., Willbold M., Raczek I., Stoll B., Herwig Kirstin. Chemical Characterisation of the USGS Reference Glasses GSA-1G, GSC-1G, GSD-1G, GSE-1G, BCR-2G, BHVO-2G and BIR-1G Using EPMA, ID-TIMS, ID-ICPMS and LA-ICP-MS. Geostandards and Research Geoanalytical. 2005; 29(3): 285-302.

46. Jochum K.P., Weis U., Stoll B., Kuzmin D., Yang Q., Raczek I., Jacob D. E., Stracke A., Birbaum K., Frick D.A., Günther D., Enzweiler J. Determination of 
Reference Values for NIST SRM 610--617 Glasses Following ISO Guidelines. Geostandards and Research Geoanalytical. 2011; 35(4): 397-429.

47. Jarosewich E., Nelen J.A., Norberg A. Reference samples for electron microprobe analysis. Geostandards Newsletter. 1980; 4(1): 43-47.

48. Wiedenbeck M., Allé P., Corfu F., Griffin W.L., Meier M., Oberli F., von Quadt A., Roddick J.C., Spiegel W. Three natural zircon standards for U-Th-Pb, LuHf, trace element and REE analyses. Geostandard Newsletters 1995; 19: 1 -23.

49. Black L.P., Gulson, B.L. The age of the Mud Tank carbonatite, Strangways Range, Northern Territory. BMR Journal of Australian Geology and Geophysics. 1978; 3: 227-232.

50. Paces J.B., Miller J.D. Jr. Precise U-Pb ages of Duluth Complex and related mafic intrusions, Northeastern Minnesota: geochronological insights to physical, petrogenetic, paleomagnetic, and tectonomagmatic processes associated with the 1.1 Ga Midcontinent Rift System. Journal of Geophysical Research. 1993; 98: 13997-14013.

51. Black L.P., Kamo S.L., Allen C.M., Davis D.W., Aleinikoff J.N., Valley J.W., Mundil R., Campbell I.H., Korsch R.J., Williams I.S., Foudoulis C. Improved ${ }^{206} \mathrm{~Pb} /{ }^{238} \mathrm{U}$ microprobe geochronology by the monitoring of a trace-element-related matrix effect; SHRIMP, ID-TIMS, ELA-ICP-MS and oxygen isotope documentation for a series of zircon standards. Chemical Geology. 2004; 205: 115 140.

52. Black L.P., Kamo S.L., Williams I.S., Mundil R., Davis D.W., Korsch R.J., Foudoulis C. The application of SHRIMP to Phanerozoic geochronology; a critical appraisal of four zircon standards. Chemical Geology. 2003; 200: 171-188. 
53. Chang Z., Vervoort J.D., McClelland W.C., Knaack C. U-Pb dating of zircon by LA-ICP-MS. G-Cubed. 2006; 7(5): 1-14.

54. Sláma, J., J. Košler, D.J. Condon, J.L. Crowley, A. Gerdes, J.M. Hanchar, M.S.A. Horstwood, G.A. Morris, L. Nasdala, N. Norberg, U. Schaltegger, B. Schoene, M.N. Tubrett, and M.J. Whitehouse. Plesovice zircon -- A new natural reference material for U-Pb and $\mathrm{Hf}$ isotopic microanalysis. Chemical Geology. 2008; 249: $1-35$.

55. Fisher C.M., Hanchar J.M., Samson S.D., Dhuime B., Blichert-Toft J., Vervoort J.D., Lam R. Synthetic zircon doped with hafnium and rare earth elements: A reference material for in situ hafnium isotope analysis. Chemical Geology. 2011; 286: $32-47$.

56. Georg, R. B., Reynolds, B. C., Frank, M. \& Halliday, A. N. New sample preparation techniques for the determination of $\mathrm{Si}$ isotopic compositions using MC-ICPMS. Chemical Geology. 2006; 235: 95-104.

57. Pringle E. A., Moynier F., Savage P. S., Badro J., Barrat J. A. Silicon isotopes in angrites and volatile loss in planetesimals. Proceedings of the National Academy of Science (USA). 2014; 111: 17029-17032.

58. Zhang A.-Y., Zhang J., Zhang R.-F., Xue Y. Determination of stable silicon isotopes using multi-collector inductively coupled plasma mass spectrometry. Chinese journal of analytical chemistry. 2015; 43(9): 1353-1359.

59. Guitreau M., Boyet M., Paquette J.-L., Gannoun A., Konc Z., Benbakkar M., Suchorski K., Hénot J.-M. Hadean protocrust reworking at the origin of the Napier Complex (Antarctica). Geochemical Perspectives Letters. 2019; 12, 7-11. 
541 60. Zambardi T., Poitrasson F. Precise determination of silicon isotopes in silicate rock reference materials by MC-ICP-MS. Geostandards and Geoanalytical Research. 2011; 35: 89-99.

Figure and Table captions

546 Table 1. LA-MC-ICP-MS operating conditions

548 Table 2. Silicon isotope results for zircons analyzed by S-MC-ICP-MS

Table 3. External reproducibility of self-normalized standards

551

552 Table 4. Summary of Si isotope measurements by LA-MC-ICP-MS of San Carlos and 91500 normalized to NIST 612

557 Figure 1. Signal and isotope ratio evolutions throughout a typical analysis of the zircon 558 standard 91500 in spot (A) and line (B) modes using the same analytical conditions 559 (i.e., spot size of $33 \mu \mathrm{m}$, frequency of $6 \mathrm{~Hz}$, fluence of $3 \mathrm{~J} / \mathrm{cm}^{2}$ and sweeping rate of $5601.6 \mu \mathrm{m} / \mathrm{s}$ for the line mode, and). In the insets, $\delta^{29} \mathrm{Si}$ and $\delta^{30} \mathrm{Si}$ values were calculated 561 by normalization to the average ${ }^{29} \mathrm{Si} /{ }^{28} \mathrm{Si}$ and ${ }^{30} \mathrm{Si} /{ }^{28} \mathrm{Si}$ of the corresponding analysis. 562 Note that during ablation both the isotope ratios are stable, despite high intensities of 563 Si in the background (laser off).. 
Figure 2. External reproducibility of Si isotopes in different matrices. Delta values are self-normalized for each standard. Note the general better external reproducibility of line analyses compared to spots regardless of the matrix analyzed

Figure 3. Long-term ( $>2$ years) reproducibility of Si isotope signatures in 91500 (selfbracketed).

Figure 4. Silicon isotope results for zircon analysed by LA-MC-ICP-MS and S-MCICP-MS. Figure A shows the relationship between $\delta^{29} \mathrm{Si}$ and $\delta^{30} \mathrm{Si}$ for all single LAMC-ICP-MS measurements whereas B exhibits the relationship between $\delta^{29} \mathrm{Si}$ and $\delta^{30} \mathrm{Si}$ for averages of all zircon standards analyzed by LA-MC-ICP-MS and S-MC-ICPMS. Note that MUN artificial zircon standards have very light Si isotope signatures compared to natural zircons and that data align along the terrestrial mass-dependent fractionation lines, labeled EMFL and KMFL for equilibrium and kinetic fractionation, respectively.

Figure 5. Comparison between LA-MC-ICP-MS and S-MC-ICP-MS/SIMS data for zircon standards (MUN-1, 91500, AS3, KIM, Kuehl Lake, MudTank, and Plešovice) from this study and Trail et al. (2018). All data align along a line with a slope of 1, therefore, indicating very good agreement between techniques.

\section{Supplementary Table captions}

Table S1. All LA-MC-ICP-MS results for standards

Table S2. Results for Si isotope measurements by LA-MC-ICP-MS of San Carlos olivine and 91500 zircon normalized to NIST 612 
590 Table S3. All results for 91500 (self-bracketed) analyzed by LA-MC-ICP-MS in line 591 mode

592 Table S4. All Si isotope data for zircon analyzed by LA-MC-ICP-MS in line mode 593 Table S5. All raw LA-MC-ICP-MS data 

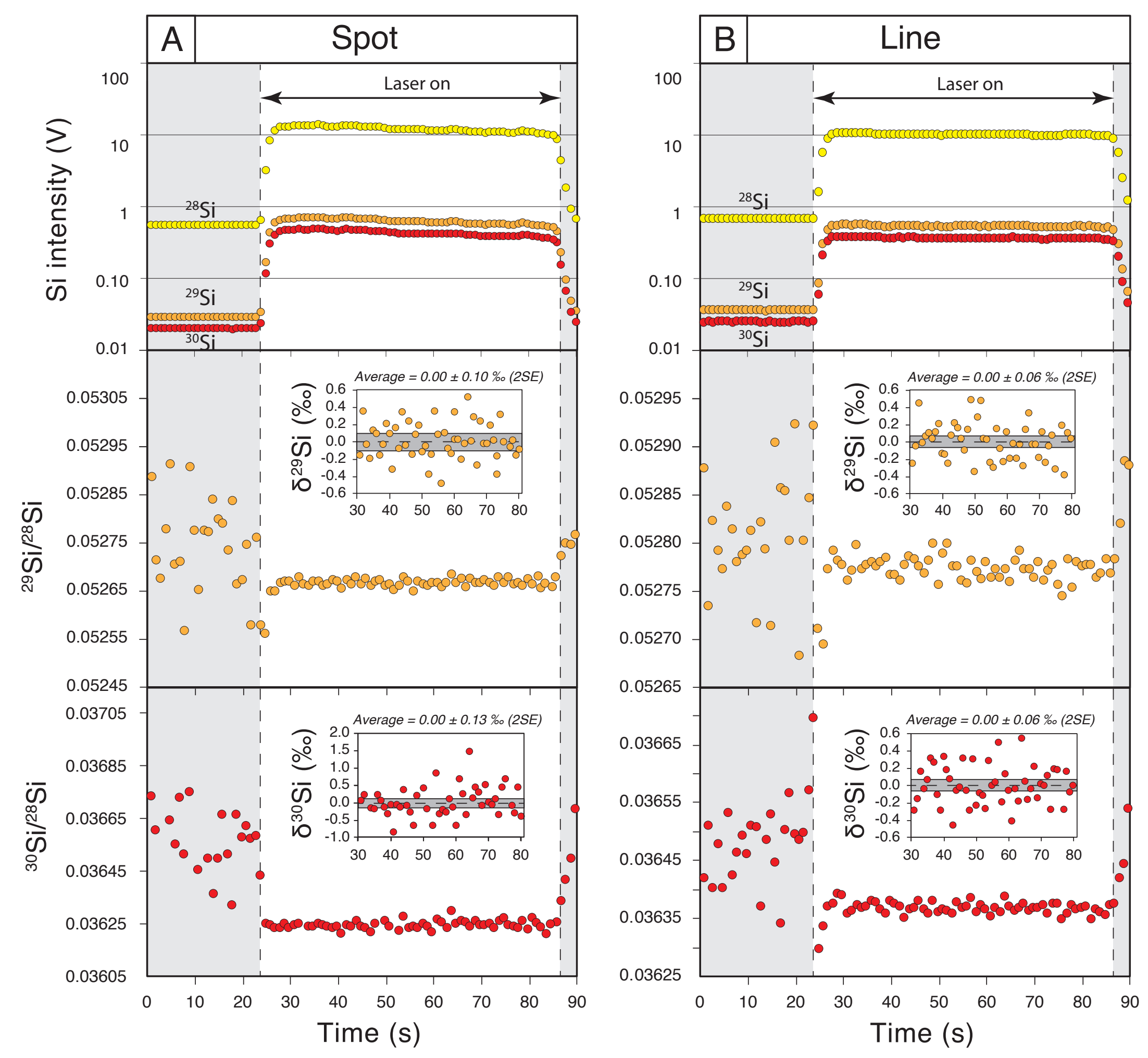
$\delta^{29} \mathrm{Si}(\%)$ self-normalized

$\delta^{30} \mathrm{Si}(\%)$ self-normalized

\begin{tabular}{llllll}
0.6 & 0.4 & 0.2 & 0.0 & 0.2 & 0.4 \\
\hline
\end{tabular} $\begin{array}{llllllll}0.8 & 0.8 & 0.0 & 0.8 & 0.8\end{array}$

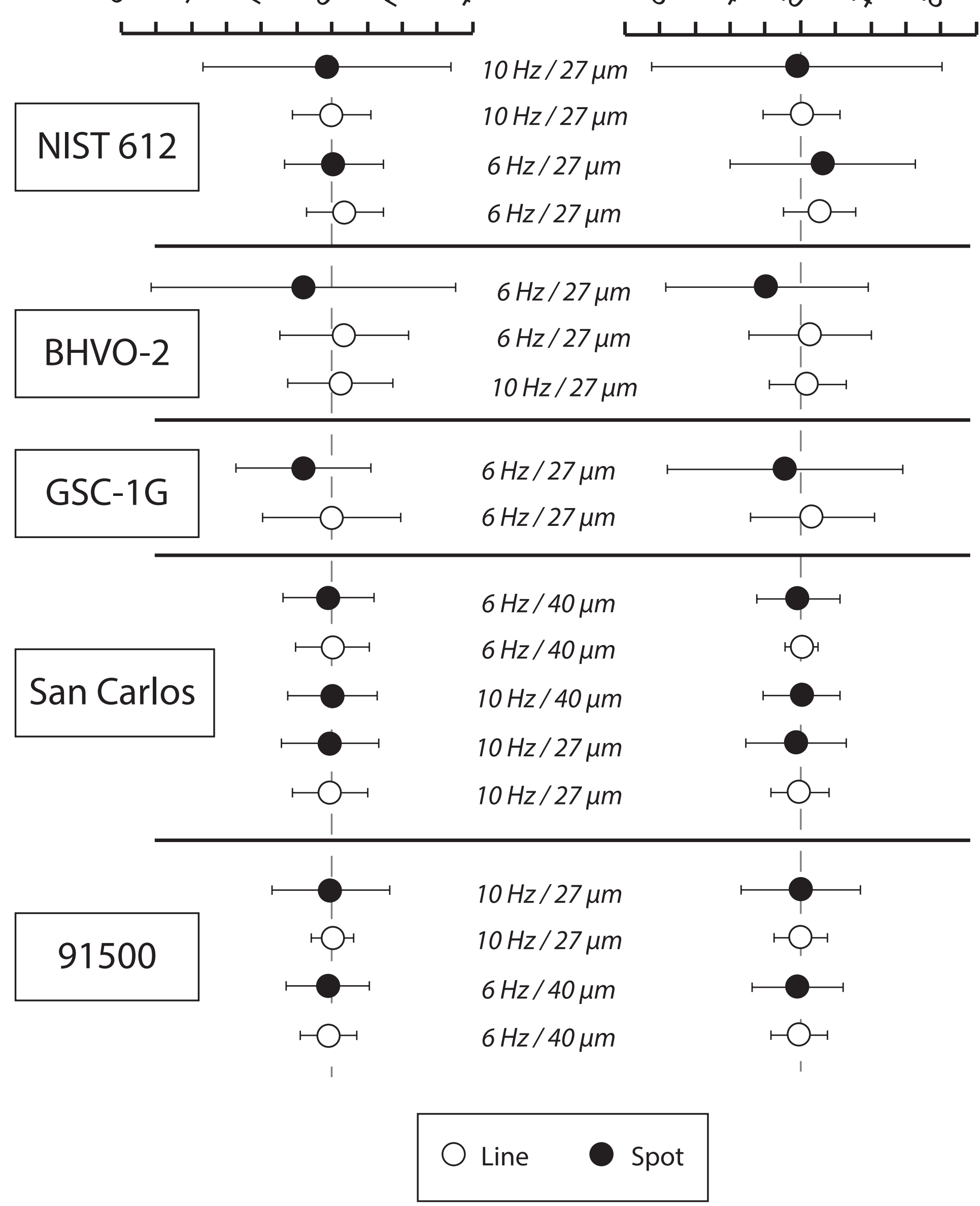




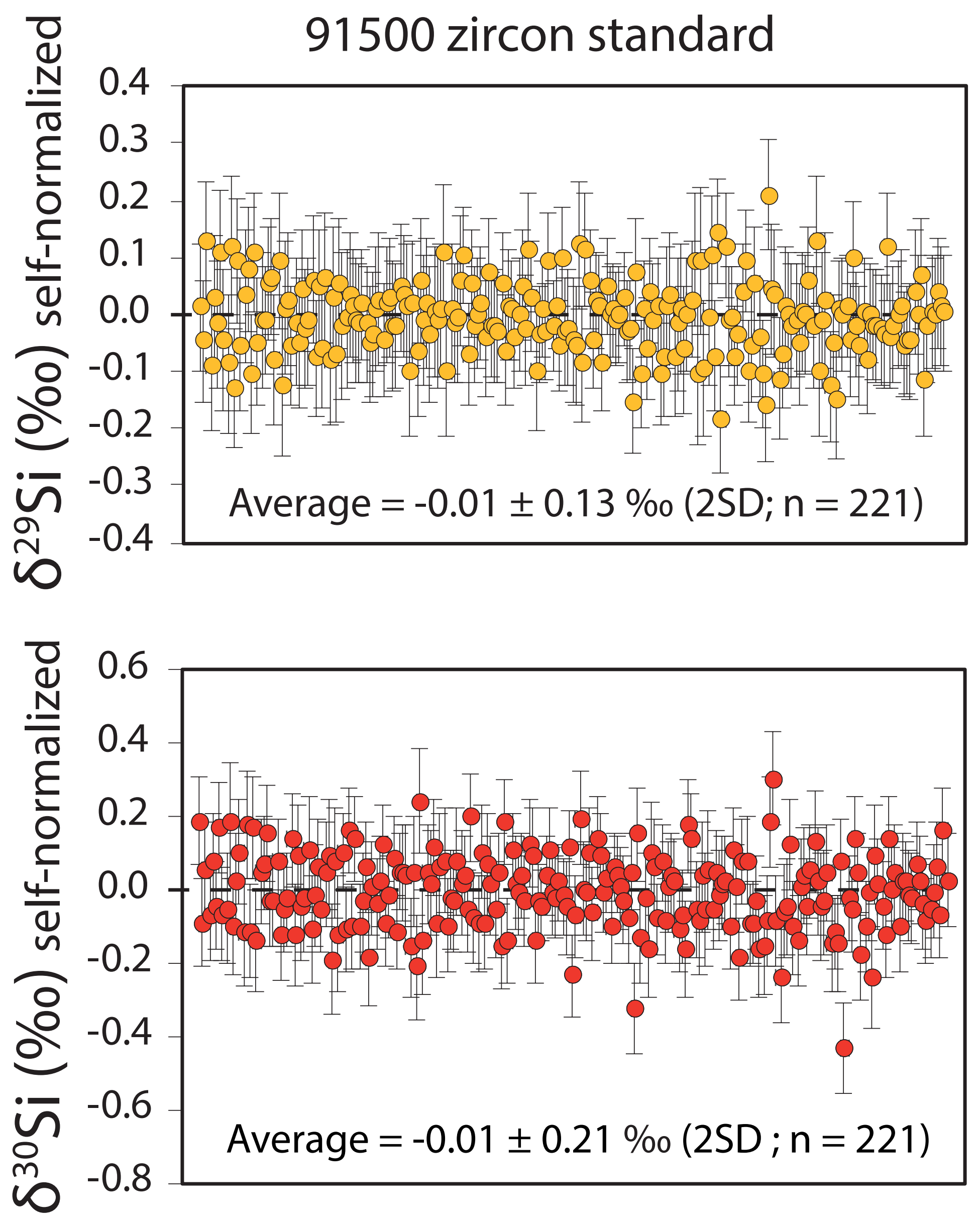


$\delta^{30} \mathrm{Si}(\% 0)$

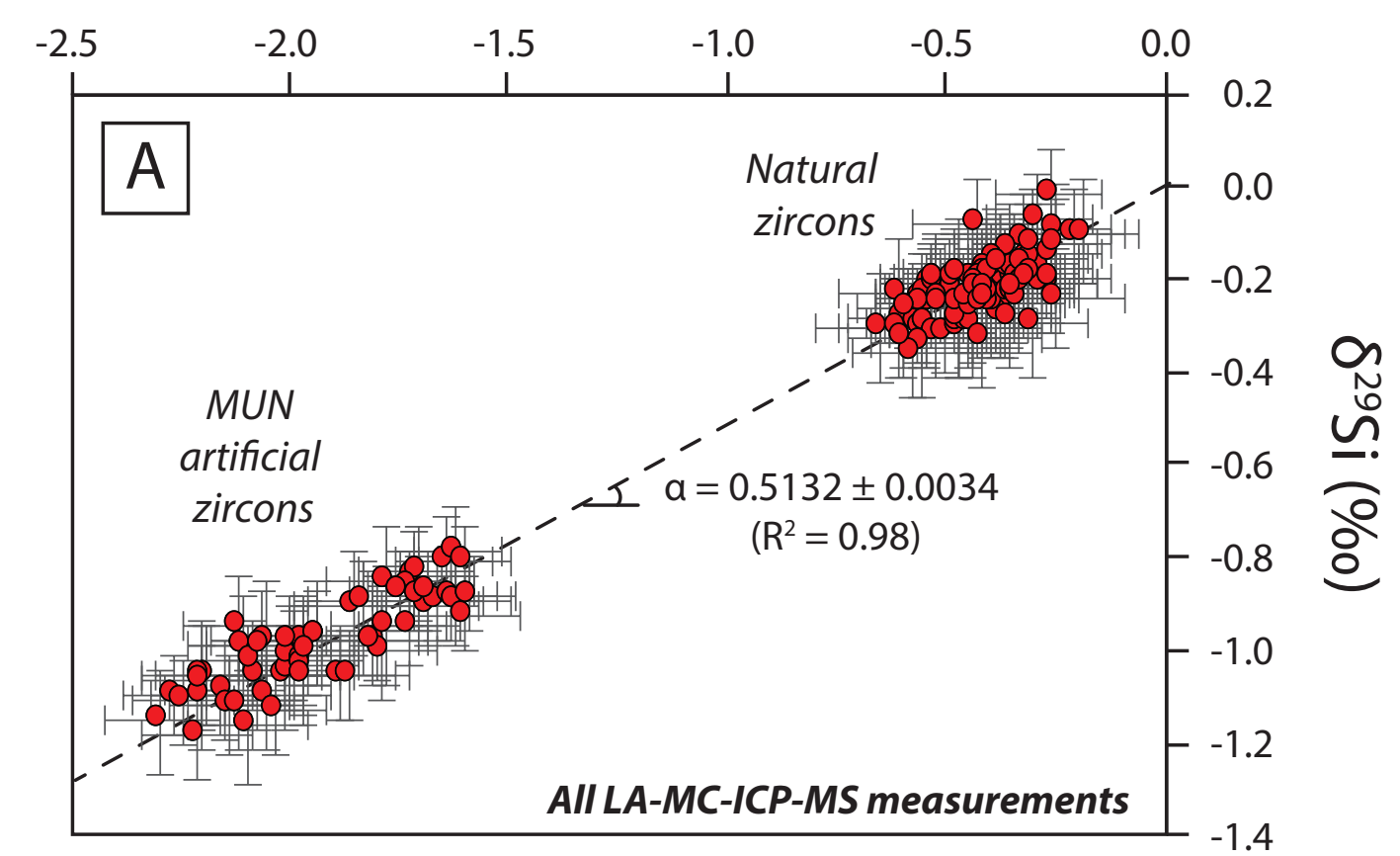

$\delta^{30} \mathrm{Si}(\% 0)$

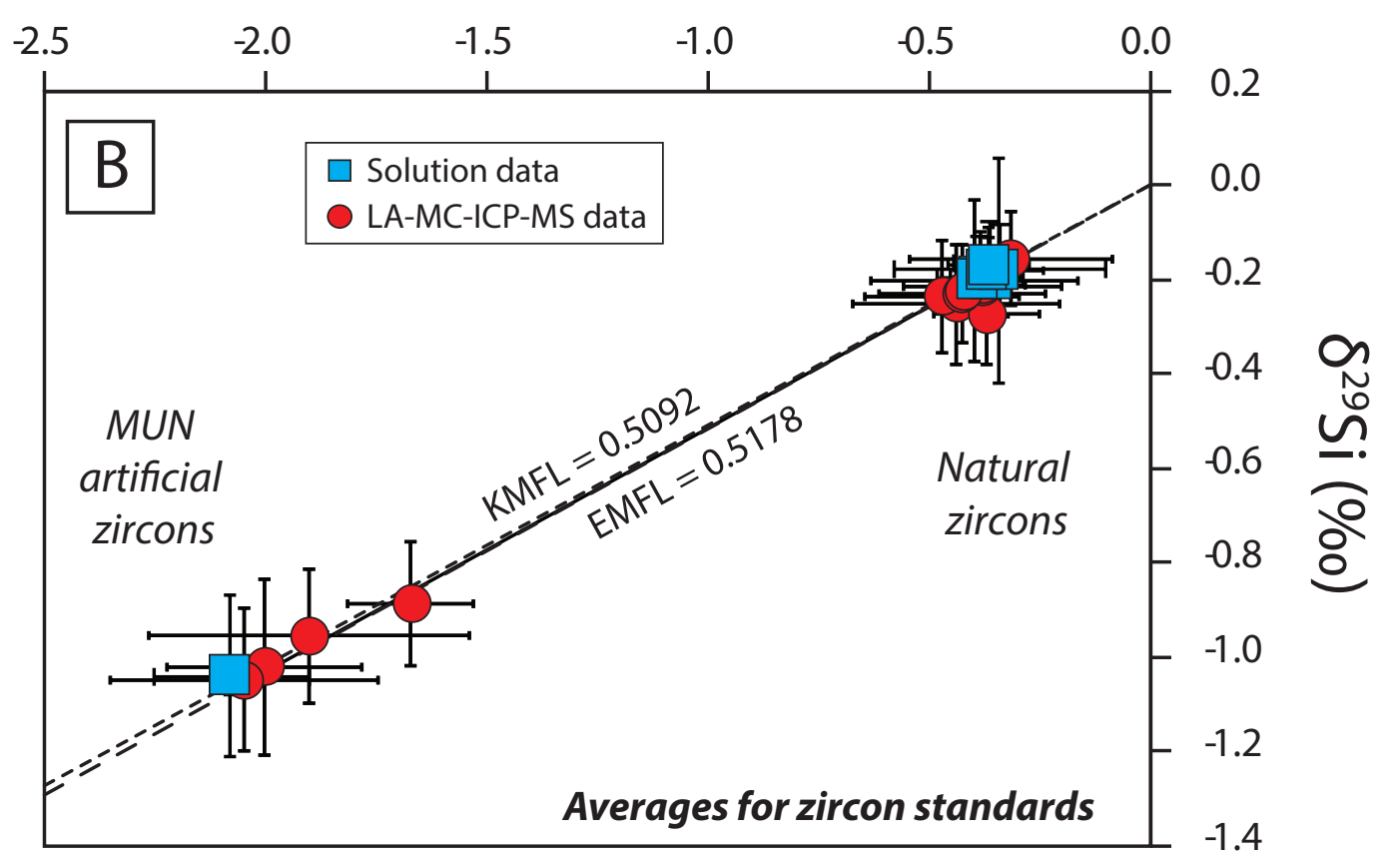




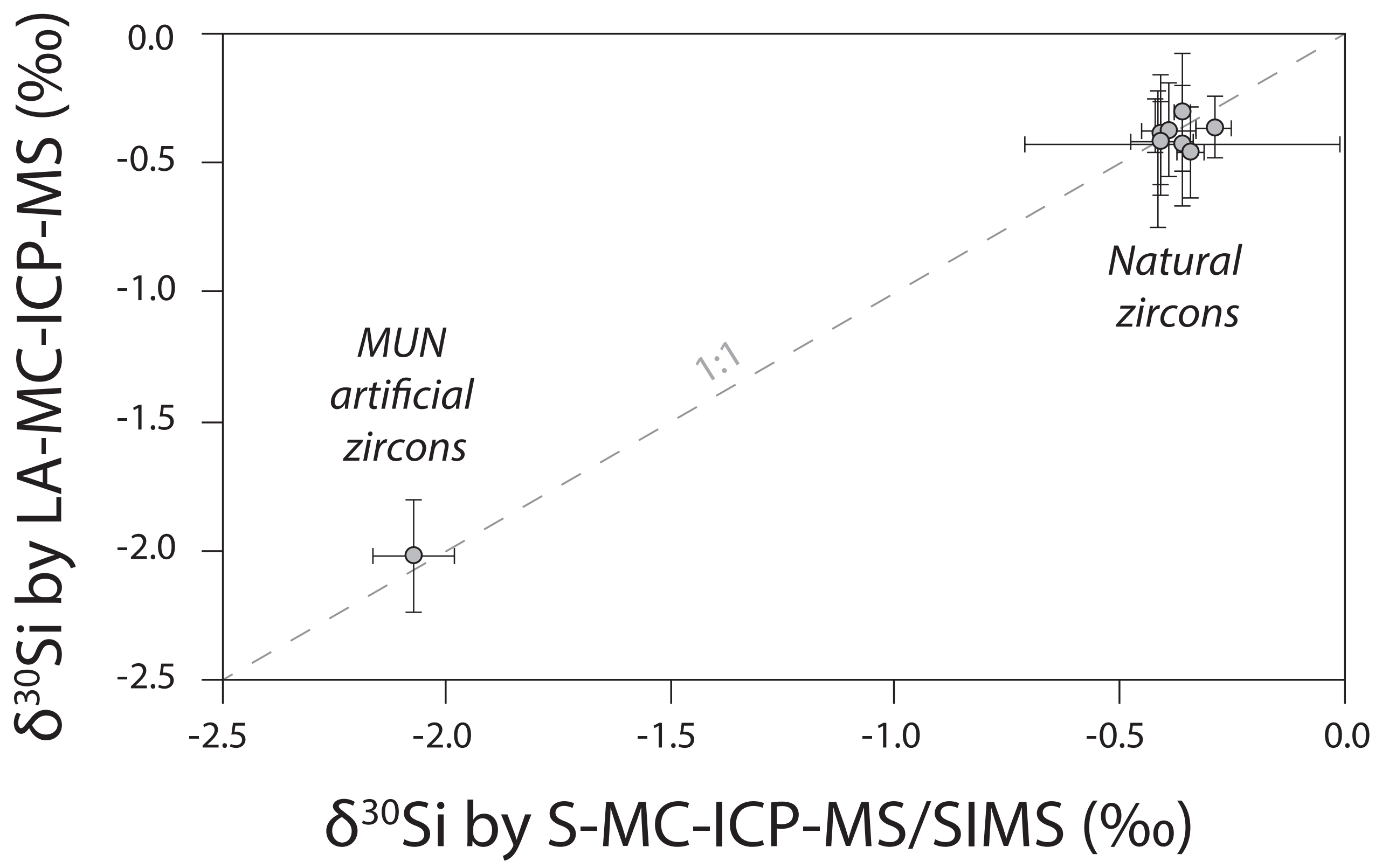


Table 1. LA-MC-ICP-MS operating conditions

\begin{tabular}{|c|c|c|c|}
\hline Analysis & & soto & \\
\hline Laboratory & & s et & \\
\hline Cup configuration & L3 & C & $\mathrm{H} 3$ \\
\hline Mass measured & 28 & 29 & 30 \\
\hline MC-ICP-MS model & The & Jept & lus \\
\hline Interface type & & se & \\
\hline Cones & & Con & \\
\hline Resistors & & ${ }^{1} \mathrm{Or}$ & \\
\hline Resolution & & $1 / \Delta \mathrm{M}$ & \\
\hline Forward Power & & 200 & \\
\hline Auxiliary gas (Ar) & & $0.8 \mathrm{~L}$ & \\
\hline Ar sample & & $1.1 \mathrm{~L}$ & \\
\hline SQUID & & On & \\
\hline Data acquisition & Tim & Ivec & ysis \\
\hline Scanning mode & & ulti-c & \\
\hline Integration time per isotope & & $1 \mathrm{~s}$ & \\
\hline Background counting time & & $0-30$ & \\
\hline Sample measurement time & & $0-60$ & \\
\hline Measurement type & & $\mathrm{d} b r$ & \\
\hline External standard & & 12 & \\
\hline Laser model & Reson & Reso & M-50E \\
\hline Wavelength & & $\overline{93 n}$ & \\
\hline Pulse duration & & $5 \mathrm{~ns}$ & \\
\hline Energy & & $-5 m$ & \\
\hline Fluence & & $\mathrm{J} / \mathrm{c}$ & \\
\hline Frequency & & -10 & \\
\hline Spot size & & -40 & \\
\hline Carrier gas & & $\mathrm{He}$ & \\
\hline Carrier gas flow & & 0.75 & \\
\hline Traverse rate & & $6 \mu \mathrm{n}$ & \\
\hline
\end{tabular}


Table 2. Si isotope results for zircons analyzed by S-MC-ICP-MS

\begin{tabular}{llllll}
\hline Sample & $\boldsymbol{\delta}^{29} \mathbf{S i}^{*}(\% 0)$ & 2SD & $\boldsymbol{\delta}^{30} \mathbf{S i}^{*}(\%)$ & 2SD & $\mathbf{n}$ \\
\hline NBS 28 (NIST 8546) & 0.00 & 0.08 & 0.00 & 0.13 & 236 \\
BHVO-2 & -0.14 & 0.09 & -0.28 & 0.15 & 60 \\
91500-MG & -0.19 & 0.09 & -0.39 & 0.10 & 4 \\
91500-Corfu & -0.20 & 0.02 & -0.36 & 0.02 & 4 \\
Plešovice-MG & -0.20 & 0.06 & -0.39 & 0.06 & 4 \\
Plešovice-IPGP & -0.18 & 0.10 & -0.34 & 0.24 & 4 \\
Plešovice-IPGP & -0.18 & 0.03 & -0.37 & 0.07 & 4 \\
Plešovice-IPGP & -0.17 & 0.09 & -0.37 & 0.08 & 4 \\
MUN-1 & -1.04 & 0.04 & -2.08 & 0.17 & 4 \\
\hline
\end{tabular}

${ }^{*}$ normalized to NBS 28 
Table 3. External reproducibility of self-normalized standards

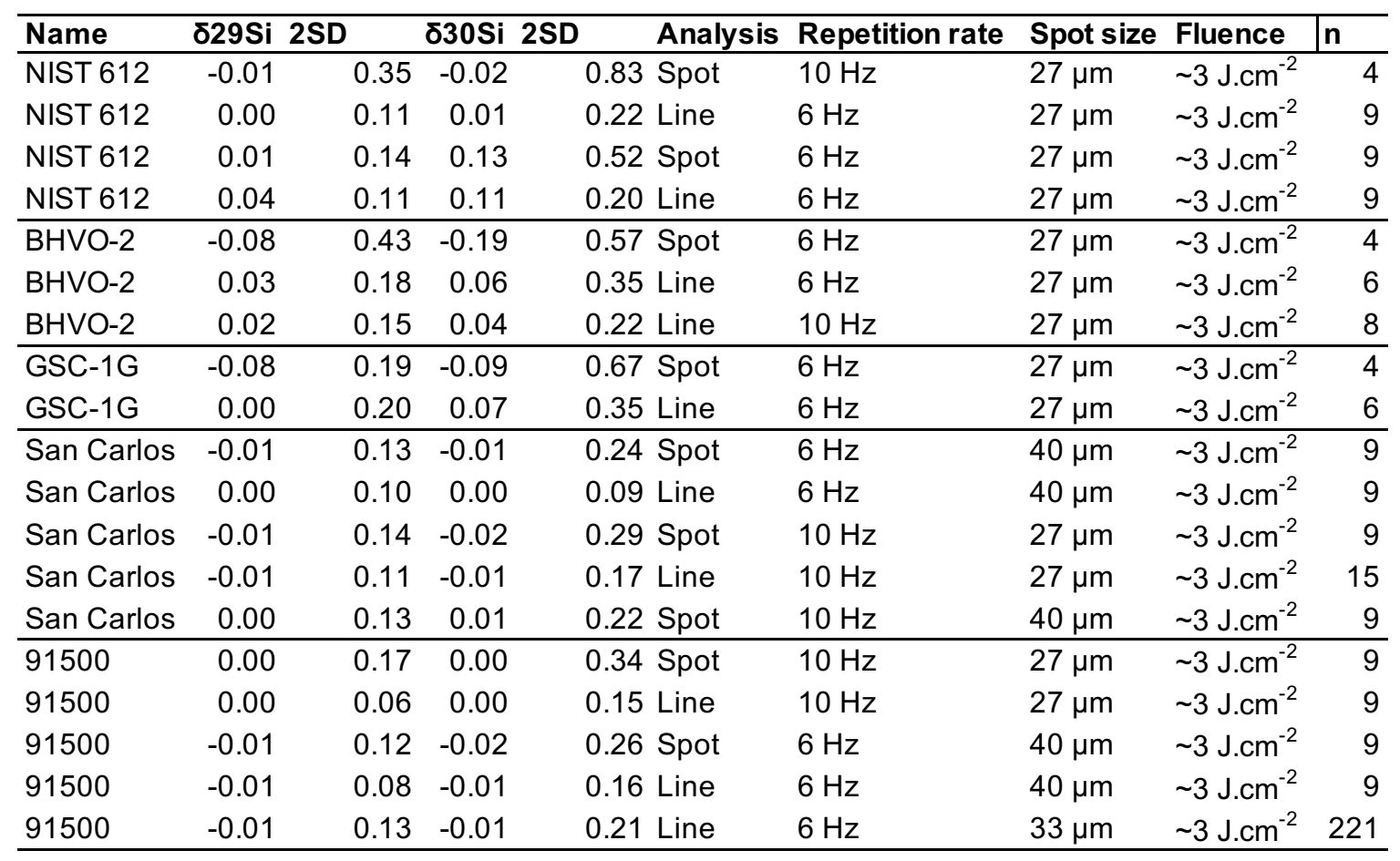




\begin{tabular}{|c|c|c|c|c|c|c|c|c|c|c|c|c|}
\hline \multirow[b]{2}{*}{ Average } & \multirow[b]{2}{*}{ ס29Si(\%o)* } & \multirow[b]{2}{*}{$2 \mathrm{SD}$} & \multirow[b]{2}{*}{ 830Si $(\% 0)^{*}$} & \multirow[b]{2}{*}{2 SD } & \multirow[b]{2}{*}{ Laser setup } & \multirow[b]{2}{*}{ Mode } & \multirow[b]{2}{*}{$\mathbf{S i}_{\mathrm{S}} / \mathbf{S i}_{\mathrm{NIST}^{* *}}$} & \multicolumn{5}{|c|}{ Literature } \\
\hline & & & & & & & & ס29Si(\%o)*** & 2 SD & $\delta 30 \mathrm{Si}(\% \circ)^{* * *}$ & 2 SD & Reference \\
\hline San Carlos & -0.74 & 0.20 & -1.44 & 0.51 & $6 \mathrm{~Hz} 40 \mu \mathrm{m}$ & Spot & 0.5 & -0.20 & 0.10 & -0.34 & 0.15 & Schuessler and Von Blackenburg (2014) \\
\hline San Carlos & -0.85 & 0.11 & -1.67 & 0.43 & $10 \mathrm{~Hz} 27 \mu \mathrm{m}$ & Spot & 0.6 & -0.20 & 0.10 & -0.34 & 0.15 & Schuessler and Von Blackenburg (2014) \\
\hline San Carlos & -0.60 & 0.08 & -1.19 & 0.22 & $10 \mathrm{~Hz} 27 \mu \mathrm{m}$ & Raster & 0.9 & -0.20 & 0.10 & -0.34 & 0.15 & Schuessler and Von Blackenburg (2014) \\
\hline 91500 & 0.19 & 0.17 & 0.37 & 0.21 & $6 \mathrm{~Hz} 40 \mu \mathrm{m}$ & Spot & 0.6 & -0.20 & 0.02 & -0.36 & 0.02 & This study \\
\hline 91500 & 0.00 & 0.31 & -0.12 & 0.48 & $10 \mathrm{~Hz} 27 \mu \mathrm{m}$ & Spot & 0.7 & -0.20 & 0.02 & -0.36 & 0.02 & This study \\
\hline
\end{tabular}

* Delta values are relative to NBS 28 but normalized to NIST 612 that was analyzed in the same conditions except for the rasters for which NIST 612 was analyzed using 6 Hz and $27 \mu \mathrm{m}$.

** $\mathrm{S}$ refers to sample (San Carlos or 91500) and NIST to NIST 612

*** Delta values are relative to NBS 28 
Table 5. Si isotope results for zircons analyzed by LA-MC-ICP-MS

\begin{tabular}{|c|c|c|c|c|c|c|c|c|c|c|}
\hline \multirow[b]{2}{*}{ Technique } & \multirow[b]{2}{*}{ Sample } & \multirow[b]{2}{*}{$\delta^{29} \mathrm{Si}^{*}(\%)$} & \multirow[b]{2}{*}{ 2SD } & \multirow[b]{2}{*}{$\delta^{30} S^{*}(\%)$} & \multirow[b]{2}{*}{ 2SD } & \multirow[b]{2}{*}{$\mathbf{n}$} & \multicolumn{4}{|c|}{ Data from other techniques } \\
\hline & & & & & & & Technique & $\delta^{30} \mathrm{Si}^{*}(\% 0)$ & 2SD & Reference \\
\hline LA-MC-ICP-MS & 91500-MG & -0.15 & 0.10 & -0.32 & 0.23 & 5 & S-MC-ICP-MS & -0.39 & 0.10 & This study \\
\hline LA-MC-ICP-MS & AS3 & -0.25 & 0.13 & -0.44 & 0.23 & 28 & SIMS & -0.36 & 0.35 & Trail et al. (2018) \\
\hline LA-MC-ICP-MS & $\mathrm{KIM}$ & -0.20 & 0.17 & -0.40 & 0.23 & 16 & S-MC-ICP-MS & -0.41 & 0.01 & Trail et al. (2018) \\
\hline LA-MC-ICP-MS & Kuehl Lake & -0.25 & 0.11 & -0.38 & 0.12 & 3 & S-MC-ICP-MS & -0.29 & 0.04 & Trail et al. (2018) \\
\hline LA-MC-ICP-MS & MudTank & -0.23 & 0.12 & -0.47 & 0.17 & 13 & S-MC-ICP-MS & -0.34 & 0.03 & Trail et al. (2018) \\
\hline LA-MC-ICP-MS & MUN-0 & -0.88 & 0.13 & -1.67 & 0.14 & 14 & - & - & - & - \\
\hline LA-MC-ICP-MS & MUN-1 & -1.02 & 0.19 & -2.00 & 0.22 & 8 & S-MC-ICP-MS & -2.08 & 0.17 & This study \\
\hline LA-MC-ICP-MS & MUN-3 & -0.95 & 0.14 & -1.90 & 0.36 & 10 & - & - & - & - \\
\hline LA-MC-ICP-MS & MUN-4 & -1.05 & 0.15 & -2.05 & 0.30 & 25 & - & - & - & - \\
\hline LA-MC-ICP-MS & Peixe & -0.23 & 0.10 & -0.43 & 0.19 & 11 & - & - & - & - \\
\hline LA-MC-ICP-MS & Plešovice-MG & -0.21 & 0.07 & -0.38 & 0.18 & 11 & S-MC-ICP-MS & -0.39 & 0.06 & This study \\
\hline LA-MC-ICP-MS & QGNG & -0.21 & 0.05 & -0.38 & 0.10 & 7 & - & - & - & - \\
\hline LA-MC-ICP-MS & R33 & -0.22 & 0.04 & -0.42 & 0.08 & 8 & - & - & - & - \\
\hline
\end{tabular}

* relative to NBS 28 